\title{
Incidence, hospital costs and in-hospital mortality rates of surgically treated patients with traumatic cranial epidural hematoma
}

Ibrahim Burak Atci, Hakan Yilmaz, Mehmet Yaman, Oguz Baran, Okan Türk, Bilgehan Solmaz, Ümit Kocaman, Nuriye Guzin Ozdemir, Nail Demirel, Ayh an Kocak TURKEY 


\title{
Incidence, hospital costs and in-hospital mortality rates of surgically treated patients with traumatic cranial epidural hematoma
}

\author{
Ibrahim Burak Atci ${ }^{1}$, Hakan Yilmaz ${ }^{2}$, Mehmet Yaman $^{1}$, Oguz \\ Baran$^{1}$, Okan Türk ${ }^{1}$, Bilgehan Solmaz ${ }^{1}$, Ümit Kocaman $^{3}$, Nuriye \\ Guzin Ozdemir ${ }^{1}$, Nail Demirel ${ }^{1}$, Ayh an Kocak ${ }^{1}$ \\ ${ }^{1}$ Istanbul Research and Training Hospital, Department of Neurosurgery, Istanbul, TURKEY \\ ${ }^{2}$ Usak University Hospital, Department of Neurosurgery, Usak, TURKEY \\ ${ }^{3}$ Izmir Cigli Research and Training Hospital, Department of Neurosurgery, Izmir, TURKEY
}

\begin{abstract}
Background: In this study, the patients who were operated in two clinics due to traumatic cranial epidural hematoma $(\mathrm{EDH})$ were assessed retrospectively and the factors that increase the costs were tried to be revealed through conducting cost analyses. Methods: The patients who were operated between 2010 and 2016 with the diagnosis of EDH were assessed in terms of age, sex, trauma etiology, Glasgow coma scale (GCS) at admission, the period from trauma to hospital arrival, trauma-related injury in other organs, the localization of hematoma, the size of hematoma, length of stay in the intensive care unit (ICU), length of antibiotherapy administration, number of consultations conducted, total cost of in-hospital treatments of the patients and prognosis. Results: Distribution of GCS were, between 13-15 in 18 (36\%) patients, 9-13 in $23(46 \%)$ patients and 3-8 in $9(18 \%)$ patients. The reasons for emergency department admissions were fall from high in $29(58 \%)$ patients, assault in $11(22 \%)$ patients and motor vehicle accident in $10(20 \%)$ patients. The average cost per ICU stay was 2838 \$ (range $=343-20571 \$$ ). The average cost per surgical treatment was $314 \$$. ICU care was approximately 9 times more expensive than surgical treatment costs. The mortality rate of the study cohort was $14 \%$ ( 7 patients). Conclusion: The prolonged period of stay in the ICU, antibiotherapy and repeat head CTs increase the costs for patients who are surgically treated for EDH.
\end{abstract}

Key words: Antibiotherapy, cost analysis, epidural hematoma, traumatic

\section{Introduction}

Epidural hematoma (EDH), which was defined for the first time by Hutchinson in
1867 , is a common type of traumatic brain injury (TBI) in which blood accumulation occurs between the dura mater and the 
cranium due to trauma. It is 4 times more common in men than in women. Although middle meningeal artery is responsible in $85 \%$ of the analyzed case series, life-threatening hemorrhages can also be observed as a result of venous hemorrhages. The mass effect of the blood results in pupillary anomalies, neurological deficits, loss of consciousness and high mortality. The mortality rates vary between \%5-45 and immediate surgical intervention is of the utmost importance in required cases [1-3].

In this study, the medical records of 50 patients with EDH who were surgically treated in 2 clinics were assessed retrospectively and the factors for increased patient costs were analyzed.

\section{Methods}

The patients who were surgically treated for traumatic EDH in two clinics between January 2010 and January 2016 were included in this retrospective study. The assessed data were as follows: age, gender, trauma etiology, Glasgow coma scale at admission, the period from trauma to hospital arrival, traumarelated injury in other organs, the localization of hematoma, the size of hematoma, length of stay in the intensive care unit (ICU), length of antibiotherapy administration, number of consultations conducted, total cost of inhospital treatments of the patients and prognosis.

All statistical analyses were performed using Statistical Package for the Social Sciences version 15 (SPSS Inc., Chicago, USA). The results were expressed as mean \pm standard deviation or frequency (\%). The Student's t- test was used to determine the significance of the differences among groups. A p value of $<0.05$ was considered statistically significant.

\section{Results}

Of all patients, 46 (92\%) were men and 4 (8\%) were women.The mean age of the patients was $35.4 \pm 5.6$ years (range $=7$ months68 years). Regarding admission GCS, the scores ranged between $13-15$ in 18 (36\%) patients, $9-13$ in 23 (46\%) patients and 3-8 in 9 (18\%) patients.

The most common reason for emergency department admissions was fall from high (58\%), followed by assault (22\%) and motor vehicle accident (MVA) (20\%)(Table 1). Forty-two (84\%) patients were admitted to the emergency department within 4 hours of trauma. The concomitant systematic injuries were as follows: extremity fractures in 10 patients, lung contusion in 4 patients, liver laceration in 3 patients, retroperitoneal hemorrhage in 2 patients and non-significant spinal fractures in 8 patients. Besides concomitant systematic injuries, 35 patients had concomitant cranial pathologies. There were linear skull fracturesin 44 patients, depression fractures in 5 patients, subdural hematoma in 4 patients, and intracerebral hematoma in 2 patients. All patients were diagnosed with computed tomography (CT) scans. The intraoperative evaluation revealed that the most common localization of EDH was temporal (36\%), followed by temporoparietal (24\%) and frontal (14\%) (Table 2). The thickness of epidural hematoma was between $10-15 \mathrm{~mm}$ in $10(20 \%)$ patients, $15-30 \mathrm{~mm}$ in $32(64 \%)$ patients and $>30 \mathrm{~mm}$ in $8(16 \%)$ patients. 
Thirty-eight (76\%) patients were taken to ICU post-operatively, and 12 (24\%) patients were taken to neurosurgery clinic beds. The average length of stay in the ICU was 8.6 days (range $=1-60$ days). The daily average cost of ICU was $343 \$$ and the average cost per ICU stay was 2838 (range $=343-20571 \$$ ) (Table 3, Figure 1). The average cost per surgical treatment was 314 \$. ICU care was approximately 9 times more expensive than surgical treatment costs. During ICU followup, an average of $3.8 \quad$ (range $=2-13$ ) neurosurgery consultations was performed per patient. Seven patients died in the ICU and the mortality rate of the study cohort was $14 \%$. The admission GCS values of these 7 patients were below 6. Besides, all these 7 patients had other concomitant intracranial pathologies and they were operated within 4 hours following the trauma.

Thirty-one patients were taken to service beds following ICU follow-up. The average length of service bed stay was 5.7 days (range $=1-28$ days) for the remaining 43 patients. The average cost per service bed stay was 2057 \$ (range=1285-3428 \$). During service stay, patients had undergone an average of 3.7 (range $=2-10$ ) repeat head CTs. Except for the post-operative early control CT, none of the other control CTs demonstrated a surgical pathology and affected the treatment.

All patients in this study received prophylactic ceftriaxone treatment. During ICU follow-up, following pathologic agents were cultivated in serum, urine, feces and tracheal samples: Methicillin-resistant Staphylococcus aureus (MRSA) in 4 samples, Acinetobacter baumannii in 2 samples,
Enterococcus faecalis in 3 samples, and Klebsiella pneumonia in 2 samples. Double or triple antibiotherapy was administered to these cases for an average of 10 days. Double antibiotherapy was applied and continued for 7 days in another group of 10 patients due to fever although no pathologic agent could be cultivated and their white blood cells (WBC) were within normal ranges. To sum up, double or triple antibiotherapy was administered to 21 patients and these treatments continued for 7-10 days. The total cost of antibiotics constituted $15 \%$ of total cost of stay. The total cost of patients who stayed in the ICU for $\geq 10$ days and who had double antibiotherapy were significantly higher than the total cost of other patients $(\mathrm{p}<0.05)($ Table 4$)$.

Regarding Glasgow outcome scale (GOS), thirty-five patients were discharged with low disability (GOS 5), four patients with moderate disability (GOS 4), three patients with severe disability (GOS 3), and one patient with persistent vegetative state (GOS 2) (morbidity rate $=16 \%$ ) (Table 5). All the patients who were discharged with GOS 3 and 2 were $\geq 50$ years of age.

When GCS is correlated with cost analysis, a GCS value of $\leq 8$ was statistically significantly correlated with cost $(\mathrm{p}<0.05)$.

\section{TABLE 1}

Trauma etiology

\begin{tabular}{|l|l|}
\hline Etiology & $\begin{array}{l}\text { Patient number and } \\
\text { percentage }\end{array}$ \\
\hline Falling from high & $29(\% 58)$ \\
\hline Assault & $11(\% 22)$ \\
\hline Traffic accident & $10(\% 20)$ \\
\hline
\end{tabular}


TABLE 2

The localization of epidural hematoma

\begin{tabular}{lc}
\hline Localization & $\begin{array}{l}\text { Patient number and } \\
\text { percentage }\end{array}$ \\
\hline Temporal & $18(\% 36)$ \\
Temporoparietal & $12(\% 24)$ \\
Frontal & $7(\% 14)$ \\
Parietal & $6(\% 12)$ \\
Occipital & $5(\% 10)$ \\
Posterior fossa & $2(\% 4)$ \\
\hline
\end{tabular}

TABLE 3

The daily average cost of ICU

\begin{tabular}{|l|l|l|}
\hline Department & ICU & ICU \\
\hline & mean charge & \% of total \\
\hline Blood processing & $21.26 \$$ & $6.2 \%$ \\
\hline Central supply & $45.27 \$$ & 13.2 \\
\hline Pharmacy without antibiotics & $35.32 \$$ & 10.3 \\
\hline Antibiotherapy (average) & $\mathbf{5 1 . 4 5} \$$ & $\mathbf{1 5}$ \\
\hline ICU physician & $6.86 \$$ & 2 \\
\hline Labaratory & $116.96 \$$ & 34.1 \\
\hline Radiology & $33.95 \$$ & 9.9 \\
\hline Inhalation theraphy & $31.89 \$$ & 9.3 \\
\hline Total & $\mathbf{3 4 3} \$$ & $\mathbf{1 0 0}$ \\
\hline
\end{tabular}

TABLE 4

Antibiotic use, total financial effects and CT application rates of these patients

\begin{tabular}{|c|c|c|c|}
\hline Antibiotic use & $\begin{array}{l}\text { Double or } \\
\text { triple anti } \\
\text { biotherapy }\end{array}$ & $\begin{array}{l}\text { Double anti } \\
\text { biotherapy }\end{array}$ & $\begin{array}{l}\text { Single anti } \\
\text { biotherapy }\end{array}$ \\
\hline $\begin{array}{l}\text { Period of } \\
\text { antibiotic use } \\
\text { (average) }\end{array}$ & 10 days & 7 days & 5 days \\
\hline $\begin{array}{l}\text { Reproduction } \\
\text { status }\end{array}$ & $\begin{array}{l}4 \text { MRSA } \\
3 \text { Enterococcus } \\
2 \text { Acinetobacter } \\
2 \text { Klebsiella }\end{array}$ & $\begin{array}{l}\text { No } \\
\text { reproduction } \\
\text { (high WBC, } \\
\text { fever) }\end{array}$ & $\begin{array}{l}\text { No } \\
\text { reproduction }\end{array}$ \\
\hline Total & $\begin{array}{l}11 \text { patients } \\
(\% 22)\end{array}$ & $\begin{array}{l}10 \text { patients } \\
(\% 20)\end{array}$ & $\begin{array}{l}29 \text { patients } \\
(\% 58)\end{array}$ \\
\hline Total cost (\%) & $\% 40$ & $\% 28$ & $\% 32$ \\
\hline $\begin{array}{l}\text { CT } \\
\text { application } \\
\text { (average: } 3.7 \text { ) }\end{array}$ & 6 & 4.6 & 2.5 \\
\hline
\end{tabular}

TABLE 5

Distribution of patients according to GOS

\begin{tabular}{|l|l|l|}
\multicolumn{3}{c}{ results at discharge } \\
\hline GOS & Number & $\%$ \\
\hline $\mathbf{1}$ & 7 & 14 \\
\hline $\mathbf{2}$ & 1 & 2 \\
\hline $\mathbf{3}$ & 3 & 6 \\
\hline $\mathbf{4}$ & 4 & 8 \\
\hline $\mathbf{5}$ & 35 & 70 \\
\hline
\end{tabular}

\section{Discussion}

Acute EDH constitutes 2.7-11\% of TBIs. It is frequently seen in men and young adults. Regarding analyzed cases, it was seen on lateral surfaces of hemispheres having 70\% frequency for central pterion. The most commonly reported causes in the literature are falls, MVAs, and assaults. The incidence is lower in children and elderly, as there is close relationship between the dura and the osseous skull $[2,3]$.

There were linear fractures in $60 \%$ of the skull X-rays in our study group and standard diagnostic procedure was cranial CT. Compared to X-rays, linear fractures or complicated compression fractures are more frequently observed at the level of hemorrhage in cranial CTs. There is not a consensus to decide which patients will be a candidate for surgical procedure, but a close neurologic and radiologic follow-up is required for foreseeing hematoma growth. Generally, symptomatic EDHs should be correlated with GCS, and surgery should be planned in cases when the thickness of hematoma exceeds $15 \mathrm{~mm}$ [4-7]. In the literature, the most important determinant for prognosis and outcome is GCS. Although the general mortality rate is $20-55 \%$, it is $5-10 \%$ in early diagnosed and 
intervened cases [4, 7]. In our study, it was observed that mortality rate decreased and prognosis was better in younger patients and patients with higher GCS values.

Since brain injuries frequently include multiple trauma and multiple organ injuries, they require ICU follow-up and treatment. Many patients are also followed up by Anesthesia physicians in ICUs during the postoperative period. Immobile patients become susceptible to infections in the ICUs. It was found that the cost increased incrementally with prolonged stay in the ICU. The reasons for increased costs were analyzed in our study. Daily price for ICU standard bed is determined by the Ministry of Health. However, this standard price can be surpassed quite often with costs of examination, treatment and imaging studies, and the institution can experience financial losses. The main reasons for high costs are infection prophylaxis, and broad spectrum combined antibiotics administered to infected cases. The period before an Infectious Disease Clinic consultation and antibiotherapy application is 3 days at maximum particularly in patients who are brought to ICU intubated during the postoperative period because of low GCS. The reason for this is pulmonary infections, which occurs following air passage to bronchi after ventilation and passing through physiological ways. Central nervous system (CNS) infection is not frequent in EDHs as they are usually in the form of closed fractures. Nevertheless, CNS infection rates increase in patients with skull base involvement, and pneumocephalus, rhinorrhea or otorrhea. In these situations, short-term prophylactic antibiotherapy can be applied in selected cases. Besides, the risk for atelectasis increases in postoperatively immobile patients andcombined antibiotherapy is applied rapidly due to increased body temperature and leukocytosis. Usually prophylactic administration is performed before the results of cultures. The most important factors that can reduce costs, and mortality and morbidity rates in these patients are shortening ICU stay, weaning from mechanical ventilation within the shortest time possible, and mobilization. Furthermore, another factor that increases the costs is the prophylactic antibiotherapy with the prediagnosis of CNS infection or pulmonary infection. In our study, the costs of antibiotherapy constituted $15 \%$ of the total costs. The antibiotherapy costs of patients who stayed in the ICU for 10 or more days and who had double or triple antibiotherapy were significantly higher than other patients.

Another postoperative cost increasing factor is frequently performed neuroimaging studies. Cranial CT is the most frequently used imaging modality during the pre- and postoperative periods in EDH. The follow-up is made with frequent cranial CTs in unoperated patients $[8,9]$. In our study, the mean number of CT scans for the follow-up of EDH was 3.7. However, CT scans in ICU follow-up of patients with longer stays can range between 7-8. Yet, the data analysis revealed that CT scans, except for postoperative control brain CTs, did not affect our treatment choice. Frequent cranial CTs in the post-operative period increase the cost and also expose the patient to radiation. Close follow-up with neurological examination following CT scan 
in the postoperative early period can decrease both the costs and the risk of radiationinduced comorbidities.

\section{Conclusion}

In conclusion, the length of stay in the ICU, double or triple antibiotherapy, and frequent head CTs increase the costs for patients undergoing surgery for EDH. Though human life is a sacred phenomenon over all kinds of cost calculation, we believe institutions and patients will benefit from reduction of unnecessary antibiotherapy and limitation of frequent head CTs.

\section{What is known about this topic}

-Epidural hematoma, which was defined for the first time by Hutchinson in 1867, is a common type of traumatic brain injury (TBI) in which blood accumulation occurs between the dura mater and the cranium due to trauma.

-Patients with epidural hematoma requires ICU follow-up and treatment.

\section{What this study adds}

- The prolonged period of stay in the ICU, antibiotherapy and repeat head CTs increase the costs for patients who are surgically treated for $\mathrm{EDH}$.

\section{Correspondence}

Ibrahim Burak Atci. Istanbul Research and Training Hospital, Department of Neurosurgery; Istanbul, Turkey.

Telephone: +902124596088 Cellphone: +90 505 7733155 Fax: +902124596230

\section{E-mail:drburakatci@hotmail.com}

\section{References}

1. Sahuquillo-Barris J, Lamarca-Ciuro J, Vilalta-Castan J, Rubio-GarciaE, Rodriguez-Pazos M. Epidural hematoma and diffuse axonal injury. Neurosurgery. 1985;17(2):378379

2. Rivas JJ, Lobato RD, Sarabia R, Cordobés F, Cabrera A, Gomez P. Extradural hematoma: analysis of factors influencing the courses of 161 patients. Neurosurgery. 1988;23(1):44-51

3. Cheung PS, Lam JM, Yeung JH, Graham CA, Rainer $\mathrm{TH}$. Outcome of traumatic extradural haematoma in Hong Kong. Injury. 2007;38(1):76-80

4. Deniz FE, Türk CC, Ismailoğlu O, Bozkurt G, Ozcan OE. Rapid spontaneous resolution of epidural hematoma: a case report. Ulus Travma Acil Cerrahi Derg. 201;16(3):280-282

5. Chen TY, Wong CW, Chang CN, Lui TN, Cheng WC, Tsai MD, Lin TK. The expectant treatment of "asymptomatic" supratentorial epidural hematomas. Neurosurgery. 1993;32(2): 176-179

6. Bejjani GK, Donahue DJ, Rusin J, Broemeling LD. Radiological and clinical criteria for the management of epidural hematomas in children. Pediatr Neurosurg. 1996;25(6):302-308

7. Bezircioğlu H, Erşahin Y, Demirçivi F, Yurt I, Dönertaş $\mathrm{K}$, Tektaş S. Nonoperative treatment of acute extradural hematomas: analysis of 80 cases. J Trauma. 1996;41(4):696-698

8. Ding J, Yuan F, Guo Y, Chen SW, Gao WW, Wang G, Cao HL, Ju SM, Chen H, Zhang PQ, Tian HL. A prospective clinical study of routine repeat computed tomography (CT) after traumatic brain injury (TBI). Brain Inj. 2012;26(10):1211-1216

9. Shin DS, Hwang SC, Kim BT, Jeong JH, Im SB, Shin WH. Serial Brain CT Scans in Severe Head Injury without Intracranial Pressure Monitoring. Korean J Neurotrauma. 2014; 10(1):26-30 